\title{
Multiple Spectroscopic and Theoretical Approaches to Study the Interaction between HSA and the Antiparasitic Drugs: Benznidazole, Metronidazole, Nifurtimox and Megazol
}

\author{
Otávio A. Chaves, ${ }^{a}$ Romulo C. Ferreira, ${ }^{a}$ Lorrayne S. da Silva, ${ }^{a}$ Bruna C. E. de Souza, ${ }^{a}$ \\ Dari Cesarin-Sobrinho, ${ }^{a}$ José Carlos Netto-Ferreira, ${ }^{a, b}$ Carlos M. R. Sant'Anna ${ }^{a}$ and \\ Aurélio B. B. Ferreira*,a
}

${ }^{a}$ Departamento de Química, Universidade Federal Rural do Rio de Janeiro, BR-465 km 7, 23970-000 Seropédica-RJ, Brazil

${ }^{b}$ Instituto Nacional de Metrologia, Qualidade e Tecnologia (INMETRO), Divisão de Metrologia Química, 25250-020 Duque de Caxias-RJ, Brazil

\begin{abstract}
The interaction between four antiparasitic drugs (benznidazole (BZL), metronidazole (MTZ), nifurtimox (NFX) and megazol (MZ)) with human serum albumin (HSA), the main vehicle of biodistribution of xenobiotics, hydrophobic, small and endogenous molecules in the bloodstream, was evaluated by multiple spectroscopic techniques and theoretical calculations. In all cases quenching of the fluorescence of HSA by these drugs involve a static mechanism, due to ground state association. There is just one main binding site in HSA for these four ligands (Sudlow's site I); binding is spontaneous, moderate, does not have any effect on the polarity around the Tyr and Trp residues and does not perturb significantly the secondary structure of the protein. Molecular docking studies suggest hydrogen bonding and hydrophobic interactions as the main binding forces, i.e., BZL associates with the Trp-214 residue via hydrophobic interactions and with Gln-220, Arg-221 and Glu-449 residues via hydrogen bonding; whereas MTZ associates with Leu-197 and Leu480 residues via hydrophobic interactions and with Trp-214, Glu-449 and Ser-453 via hydrogen bonding. Furthermore, electrostatic interactions were also suggested for HSA:MZ and HSA:NFX.
\end{abstract}

Keywords: human serum albumin, antiparasitic drugs, spectroscopy, molecular docking

\section{Introduction}

Chagas disease (American trypanosomiasis) is one of the most important parasitic infections in Latin America. It has expanded from a neglected, endemic parasitic infection of the rural poor to an urbanized chronic disease. Nowadays it has become a potentially emergent global health problem. ${ }^{1}$ Chagas disease is caused by the protozoan parasite Trypanosoma cruzi, which is transmitted when the infected feces of the triatomine (in different countries, they are popularly known as: barbeiro, vinchuca, reduviid bug, kissing bug, etc.) vector are inoculated through a bite site or through an intact mucous membrane of a mammalian host. ${ }^{2}$ Two nitro heterocyclic compounds, 4-[(5-nitrofurfurylidene) amino-3-methyl thio morpholine1,1-dioxide] (nifurtimox, NFX) and $N$-benzil-2-nitro1-imidazole acetamide (benznidazole, BZL) are at present

*e-mail: aureliobf@uol.com.br used to treat Chagas disease. BZL, a nitroimidazole derivative, is better tolerated when compared to NFX, a 5-nitrofuran derivative, and is generally considered the drug of choice. ${ }^{1}$ However, other nitroimidazole derivatives showed biological activity in trials against Chagas disease. Thus, 1-(2-hydroxyethyl)-2-methyl-5-nitroimidazole (metronidazole, MTZ) was evaluated for patients in the acute or chronic stage in Panama, involving 1307 patients, with ages ranging from 6 months to 73 years. For patients without symptoms of cardiomyopathy (a common complication for chronic Chagas disease sufferers), in both phases of the disease, the drug was well tolerated and serological reactions were negative in all patients $(100 \%){ }^{3}$ An iodine-substituted derivative of MTZ was synthesized recently and its complex with cyclodextrin showed ten times more activity and less cytotoxicity. ${ }^{4}$ Chemotherapy of Chagas disease is still very unsatisfactory due to the development of resistance in Trypanosoma cruzi as well as the severe side effects of the existing drugs. Thus, as part 
of efforts to develop new compounds aimed at the therapy of parasitic infections, a new nitroimidazole-thiadiazole derivative 5-(1-methyl-5-nitro-1H-2-imidazolyl)1,3,4-thiadiazol-2-amine (megazol, MZ) was proposed as a potential alternative, even though it presents high toxicitiy. ${ }^{5}$ Subsequently, several structural changes were introduced in MZ, including substitution on the two rings of the basic nucleus, replacement of the thiadiazole by an oxadiazole, replacement of the nitroimidazole part by a nitrofuran or a nitrothiophene, and substitutions on the exocyclic nitrogen atom; however, megazol is still more biologically active than its derivatives. ${ }^{6,7}$

Human serum albumin (HSA) is one of the main water soluble proteins in the bloodstream. Among its functions stands out the biodistribution of different classes of drugs and xenobiotics, as well as small, hydrophobic, endogenous and exogenous molecules. It accounts for about $60 \%$ of the total plasma proteins, corresponding to a concentration of $42 \mathrm{mg} \mathrm{mL}^{-1} .{ }^{8}$ Crystallographic analysis of HSA revealed that the protein is formed by 585 amino acid residues containing 17 pairs of disulfide bridges and one free cysteine, as well as three homologous $\alpha$-helical domains (I, II and III). Each domain can be divided in two sub-domains (A and B). ${ }^{9}$ HSA abundance makes it an important factor in the pharmacokinetic behavior of many drugs, affecting their efficacy and rate of delivery. This aspect has stimulated many efforts to understand what determines drug binding and whether competition equilibria could affect drug availability. Therefore, binding to HSA is also at the root of the development of new candidate drug molecules. ${ }^{10}$ In order to contribute to the future development of new nitro heterocyclic compounds and to a safe strategy for the treatment of Chagas disease, the interaction between three commercial antiparasitic drugs (BZL, MTZ and NFX, Figure 1), as well as a potential drug (MZ, Figure 1), and human serum albumin, was evaluated by multiple spectroscopic (UV-Vis, circular dichroism (CD), steady state, time-resolved, synchronous and 3D fluorescence), and theoretical, methods.

\section{Experimental}

\section{Materials}

Human serum albumin, warfarin, ibuprofen, digitoxin and phosphate-buffered saline (PBS) buffer $(\mathrm{pH}=7.4)$ were purchased from Sigma-Aldrich (Brazil). Acetonitrile (spectroscopic grade) was purchased from Vetec Química Fina, Brazil. One tablet of PBS dissolved in $200 \mathrm{~mL}$ of deionized water yields $0.01 \mathrm{M}$ phosphate buffer, $0.0027 \mathrm{M}$ $\mathrm{KCl}$ and $0.137 \mathrm{M} \mathrm{NaCl}, \mathrm{pH} 7.4$, at $298 \mathrm{~K}$. The antiparasitic compounds BZL, MTZ and MZ were a kind gift from Dr Solange L. Castro, from the Instituto Oswaldo Cruz, Manguinhos, Rio de Janeiro, Brazil. The antiparasitic drug Lampit ${ }^{\circledR}$, from which the NFX sample was extracted, was donated by the Health Ministry, Brazilian Government. NFX was extracted by pulverizing Lampit tablets ( $400 \mathrm{mg}$ each: $120 \mathrm{mg}$ NFX and excipients) and stirring with methanol ( $2 \mathrm{~mL}$ per tablet), using a magnetic stirrer, at $318 \mathrm{~K}$ for $30 \mathrm{~min}$, filtering, washing with distilled water ( $2 \mathrm{~mL}$ per tablet) and freeze-drying under vacuum. NFX purity was more than $98.5 \%$ by high-performance liquid chromatography (HPLC, C18 column, 20:80 watermethanol eluent) and confirmed by ${ }^{1} \mathrm{H}$ nuclear magnetic resonance (NMR, DMSO- $d_{6}$ solvent).

\section{Methodology for spectroscopy measurements}

Steady state fluorescence spectra were measured on a Jasco J-815 spectrometer, in a $1 \mathrm{~cm}$ quartz cell, employing a Jasco PFD-425S15F thermostatic cuvette holder. All spectra were recorded with appropriate background corrections and for this study the inner filter correction was not necessary, because at the maximum concentration used of BZL, MTZ, NFX and MZ $\left(1.15 \times 10^{-5} \mathrm{M}\right)$ the UV-Vis absorption is less than 0.1 a.u. at 280 and $340 \mathrm{~nm}$ (Figure S1 in the Supplementary Information (SI) section). Fluorescence spectra were measured in the $300-450 \mathrm{~nm}$ range, at 296, 303 and $310 \mathrm{~K}$, with excitation wavelength at $280 \mathrm{~nm}$.

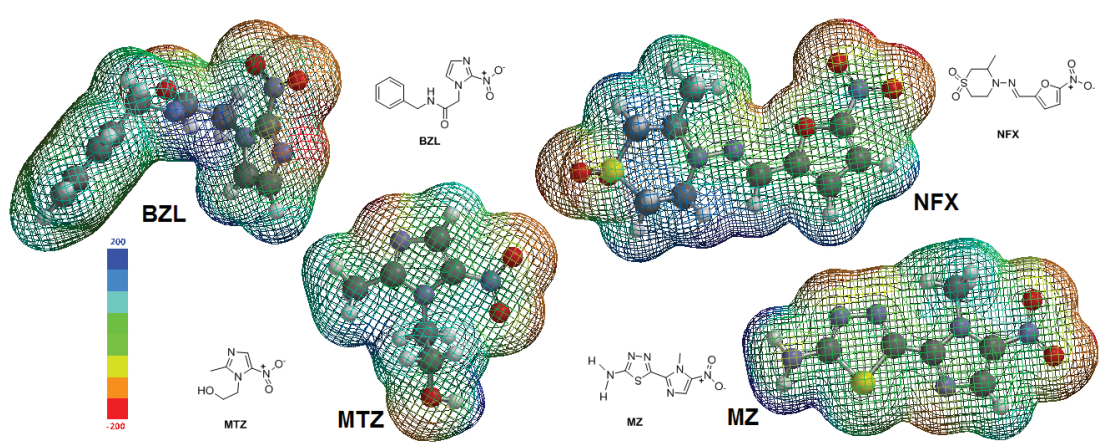

Figure 1. Electron density (red for higher, blue for lower) and chemical structures (black for carbon, white, red, blue and yellow for hydrogen, oxygen, nitrogen and sulfur, respectively) for benznidazole (BZL), metronidazole (MTZ), nifurtimox (NFX) and megazol (MZ). 
Firstly, the spectrum for a $3.0 \mathrm{~mL}$ solution containing HSA $\left(1.00 \times 10^{-5} \mathrm{M}\right.$, in PBS solution at $\left.\mathrm{pH}=7.4\right)$ was recorded. Then, the fluorescence emission spectrum of solutions resulting from successive addition of aliquots from a stock solutions of BZL, MTZ, NFX and MZ $\left(1.00 \times 10^{-3} \mathrm{M}\right.$, in acetonitrile), with final concentrations of $0.17 ; 0.33 ; 0.50$; $0.66 ; 0.83 ; 0.99$ and $1.15 \times 10^{-5} \mathrm{M}$, were also recorded.

In order to identify the main fluorescence quenching mechanism, we apply the Stern-Volmer equation (equation 1 and inset in Figure 2) and the relationship between the Stern-Volmer quenching constant $\left(\mathrm{K}_{\mathrm{SV}}\right)$ with the bimolecular quenching rate constant $\left(\mathrm{k}_{\mathrm{q}}\right)$ (equation 2): ${ }^{11}$

$$
\begin{aligned}
& \frac{\mathrm{F}_{0}}{\mathrm{~F}}=1+\mathrm{k}_{\mathrm{q}} \tau_{0}[\mathrm{Q}]=1+\mathrm{K}_{\mathrm{SV}}[\mathrm{Q}] \\
& \mathrm{k}_{\mathrm{q}}=\frac{\mathrm{K}_{\mathrm{SV}}}{\tau_{0}}
\end{aligned}
$$

where $\mathrm{F}_{0}$ and $\mathrm{F}$ are the fluorescence intensity of the
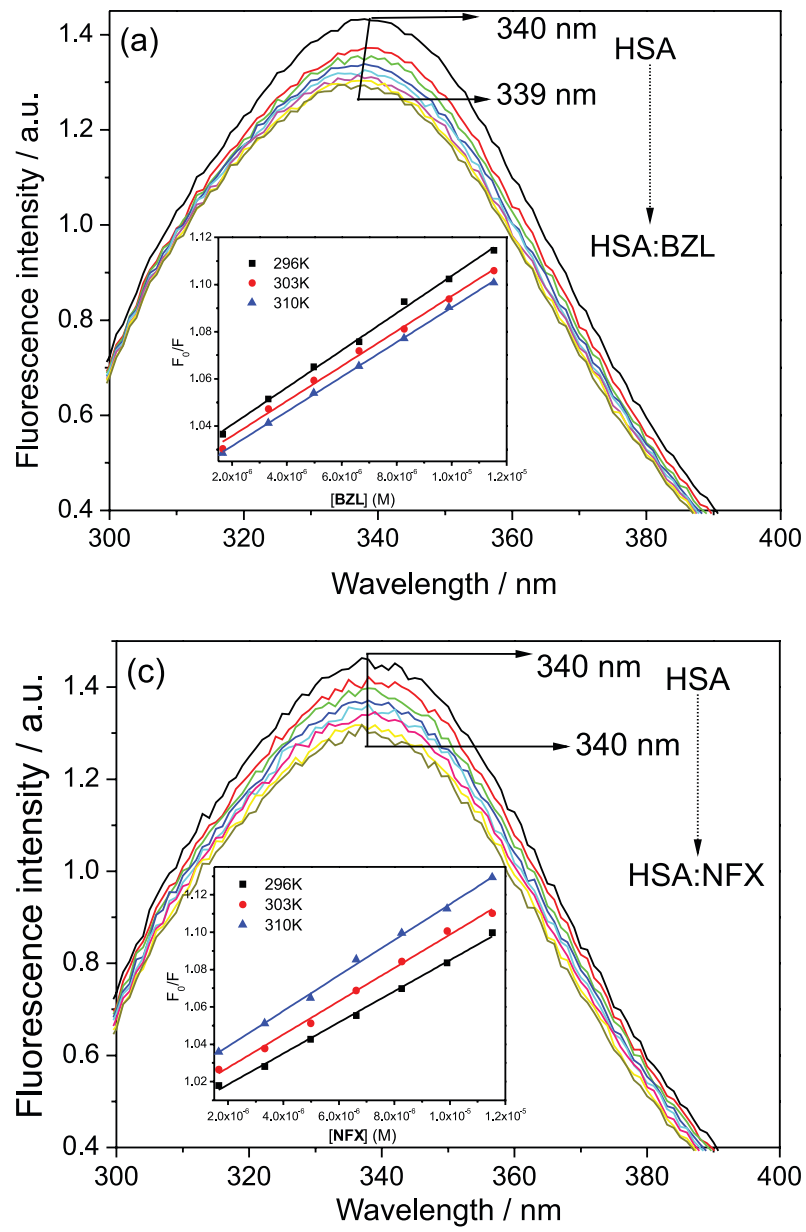

protein sample in the absence and in the presence of the quenchers, respectively; [Q] is the BZL, MTZ, NFX or MZ concentration and $\tau_{0}$ is the lifetime of the Trp-214 residue in the absence of quencher, the measured mean value for the fluorescence lifetime of HSA was $(5.68 \pm 0.10) \times 10^{-9} \mathrm{~s}$.

The binding constant between serum albumin and the samples can be determined by the modified Stern-Volmer equation $^{12}$ (equation 3 and Figure S2 in the SI section):

$\frac{\mathrm{F}_{0}}{\mathrm{~F}_{0}-\mathrm{F}}=\frac{1}{\mathrm{f}[\mathrm{Q}] \mathrm{K}_{\mathrm{a}}}+\frac{1}{\mathrm{f}}$

where $\mathrm{K}_{\mathrm{a}}$ is the modified Stern-Volmer binding constant and $\mathrm{f}$ is the fraction of the initial fluorescence intensity that corresponds to the fluorophore that is accessible to the quencher.

In order to determine the enthalpy and entropy change values for the association between HSA and the antiparasitic drugs, the van't Hoff equation (equation 4 and
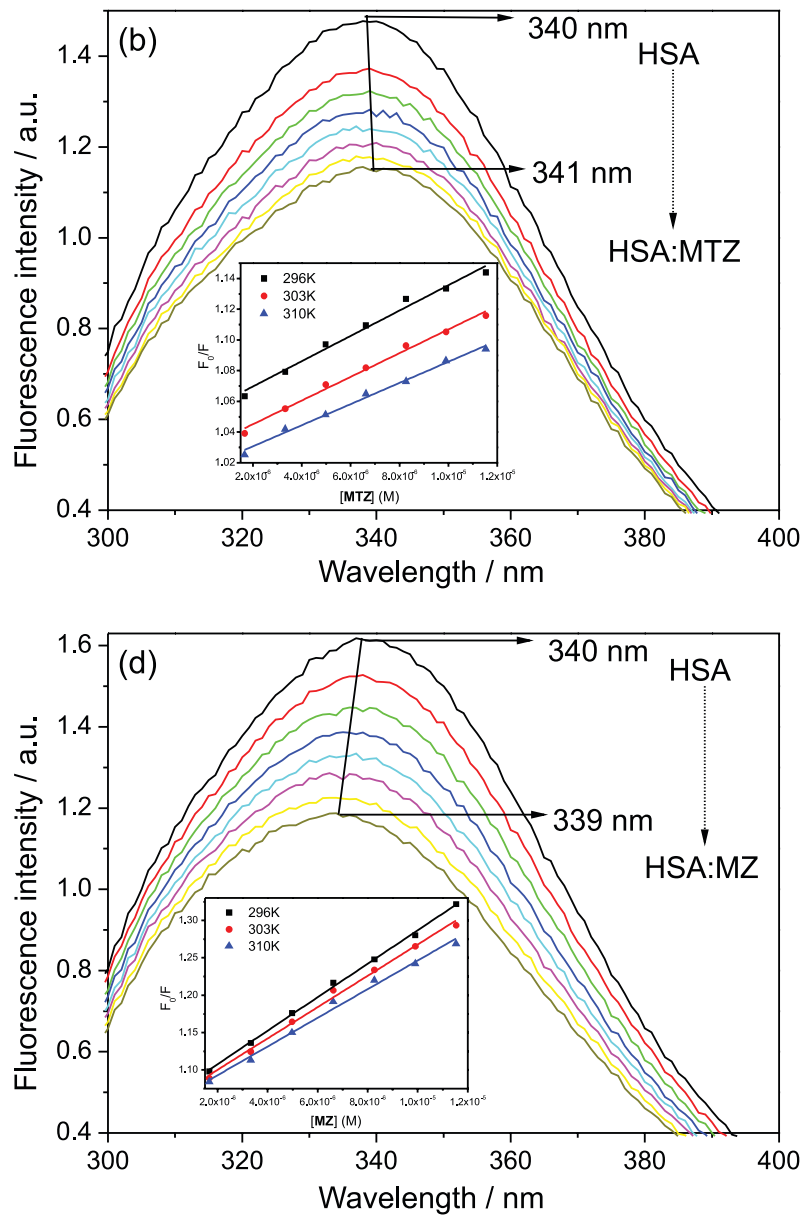

Figure 2. Fluorescence emission spectra for HSA and its fluorescence quenching with successive addition of (a) BZL; (b) MTZ; (c) NFX and (d) MZ at $310 \mathrm{~K}$. Inset: Stern-Volmer plot for the interaction between HSA:BZL, HSA:MTZ, HSA:NFX and HSA:MZ in $\mathrm{pH}=7.40 .[\mathrm{HSA}]=1.00 \times 10^{-5} \mathrm{M}$; $[\mathrm{BZL}]=[\mathrm{MTZ}]=[\mathrm{NFX}]=[\mathrm{MZ}]=0.17 ; 0.33 ; 0.50 ; 0.66 ; 0.83 ; 0.99$ and $1.15 \times 10^{-5} \mathrm{M}$. 
Figure S3 in the SI section) can be applied..$^{13}$ In addition, the spontaneity of the binding process can be calculated according to the Gibb's free energy equation (equation 5):

$\ln \mathrm{K}_{\mathrm{a}}=-\frac{\Delta \mathrm{H}^{\circ}}{\mathrm{RT}}+\frac{\Delta \mathrm{S}^{\circ}}{\mathrm{R}}$

$\Delta \mathrm{G}^{\circ}=\Delta \mathrm{H}^{\circ}-\mathrm{T} \Delta \mathrm{S}^{\circ}$

where $\mathrm{K}_{\mathrm{a}}$ is the modified Stern-Volmer binding constant at the corresponding temperature, $\mathrm{R}$ represents the gas constant $\left(8.314 \times 10^{-3} \mathrm{~kJ} \mathrm{~mol}^{-1} \mathrm{~K}^{-1}\right)$, T is the temperature $(296,303$ and $310 \mathrm{~K})$ and $\Delta \mathrm{G}^{\circ}, \Delta \mathrm{H}^{\circ}$ and $\Delta \mathrm{S}^{\circ}$ are the Gibb's free energy, enthalpy and entropy changes, respectively.

Time-resolved fluorescence measurements were performed on a spectrofluorimeter model FL920 CD, from Edinburgh Instruments, equipped with an electrically pumped laser (EPL, $\lambda_{\text {exc }}=280 \pm 10 \mathrm{~nm}$; pulse of $850 \mathrm{ps}$ and energy of $1.8 \mu \mathrm{W}$ per pulse) and monitoring emission at $340 \mathrm{~nm}$. Fluorescence decay was obtained for the free HSA solution $\left(1.00 \times 10^{-5} \mathrm{M}\right.$ in $\left.\mathrm{pH}=7.4\right)$ and for HSA solutions containing the maximum concentrations of BZL, MTZ, NFX and MZ used in the steady state fluorescence studies $\left(1.15 \times 10^{-5} \mathrm{M}\right)$, at room temperature (ca. $\left.298 \mathrm{~K}\right)$.

Synchronous fluorescence (SF) and 3D fluorescence spectra were obtained from a spectrofluorimeter model Xe900 from Edinburgh Instruments. SF spectra for HSA $\left(1.00 \times 10^{-5} \mathrm{M}\right)$ were recorded with increasing concentrations of BZL, MTZ, NFX and MZ, in the same concentration range used in the steady state fluorescence studies. The spectra were recorded in the $240-320 \mathrm{~nm}$ range by setting $\Delta \lambda=60$ and $15 \mathrm{~nm}$ for tryptophan and tyrosine residues, respectively, at room temperature (ca. $298 \mathrm{~K}$ ). 3D fluorescence spectra of HSA were recorded in the absence and presence of BZL, MTZ, NFX and MZ, using an excitation wavelength range of 200-340 nm and emission wavelength range of $200-450 \mathrm{~nm}$, at room temperature (ca. $298 \mathrm{~K}) .3 \mathrm{D}$ spectra were recorded for $3.0 \mathrm{~mL}$ of HSA solution $\left(1.00 \times 10^{-5} \mathrm{M}\right.$, in a PBS solution, $\left.\mathrm{pH}=7.4\right)$ and for HSA:BZL, HSA:MTZ, HSA:NFX and HSA:MZ in the maximum concentration of quencher used in the steady state fluorescence measurements $\left(1.15 \times 10^{-5} \mathrm{M}\right)$. The program used to plot the 3D graphics (Figure 3 ) was the same used in the 3D measurements.

Competitive binding studies were carried out with three probes widely employed for the characterization of binding sites in albumin, i.e., warfarin, ibuprofen and digitoxin for sites I, II and III, respectively. ${ }^{14} \mathrm{HSA}$ and site probes were used at a fixed concentration $\left(1.00 \times 10^{-5} \mathrm{M}\right)$ and fluorescence quenching titration (with BZL, MTZ, NFX and MZ), at $310 \mathrm{~K}$, was performed as described previously in the steady state fluorescence quenching methodology. Thus, the binding parameters for the HSA:BZL, HSA:MTZ, HSA:NFX and HSA:MZ interactions were determined in the presence of each site probe.

Circular dichroism (CD) spectra were measured on a Jasco J-815 spectrometer, in a $1 \mathrm{~cm}$ quartz cell, employing a Jasco PFD-425S15F thermostatic cuvette holder. All spectra were recorded with appropriate background corrections. CD spectra were measured in the $200-260 \mathrm{~nm}$ range, at $310 \mathrm{~K}$. Firstly, the spectrum of a free HSA solution $\left(1.00 \times 10^{-6} \mathrm{M}\right.$ in PBS solution, $\left.\mathrm{pH}=7.4\right)$ was recorded and then the spectra resulting from the addition of the maximum
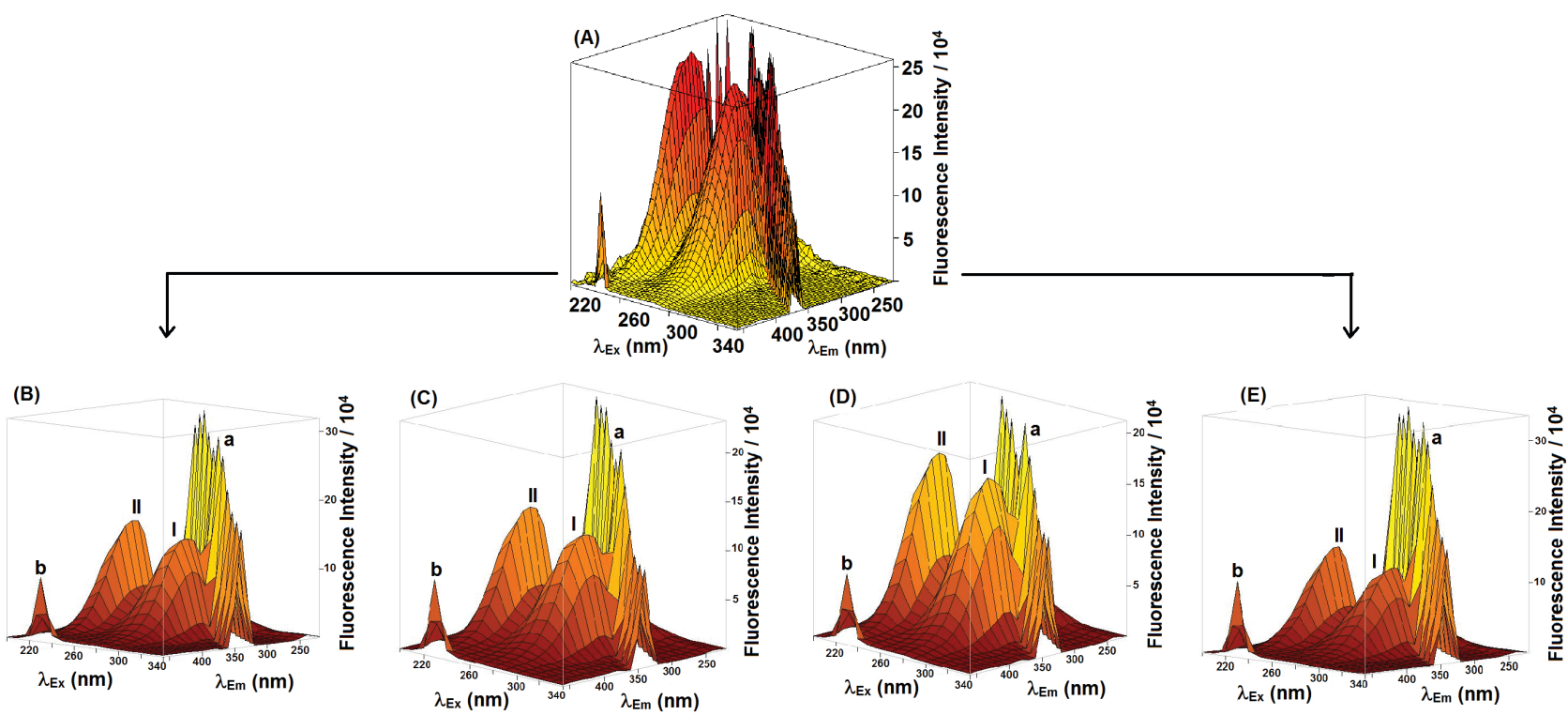

Figure 3. 3D fluorescence spectral projections for (A) HAS; (B) HSA:BZL; (C) HSA:MTZ; (D) HSA:NFX and (E) HSA:MZ, recorded in PBS solution $(\mathrm{pH}=7.40)$ at room temperature. $[\mathrm{HSA}]=1.00 \times 10^{-6} \mathrm{M} ;[\mathrm{BZL}]=[\mathrm{MTZ}]=[\mathrm{NFX}]=[\mathrm{MZ}]=1.15 \times 10^{-5} \mathrm{M}$. 
concentrations of BZL, MTZ, NFX and MZ $\left(1.15 \times 10^{-5} \mathrm{M}\right)$ to HSA solutions were also recorded.

CD results can be expressed in terms of significant molar residual ellipticity (MRE) in $\mathrm{deg} \mathrm{cm}^{2} \mathrm{dmol}^{-1}$, calculated according to equation $6::^{14}$

$$
\mathrm{MRE}=\frac{\theta}{\left(10 \mathrm{nlC}_{\mathrm{p}}\right)}
$$

where $\theta$ is the observed $\mathrm{CD}$ (in milli-degrees), $\mathrm{n}$ is the number of amino acid residues (585 for HSA), ${ }^{15} 1$ is the path length of the cell (in $\mathrm{cm}$ ) and $\mathrm{C}_{\mathrm{p}}$ is the molar concentration of HSA $\left(1.00 \times 10^{-6} \mathrm{M}\right)$.

The $\alpha$-helical content of free HSA, as well as bound with BZL, MTZ, NFX and MZ, can be calculated from the molar residual ellipticity (MRE) values at 208 (equation 7) and $222 \mathrm{~nm}$ (equation 8):

$$
\begin{aligned}
& \% \alpha \text {-helix }=\left[\frac{\left(-\mathrm{MRE}_{208}-4000\right)}{33000-4000}\right] \times 100 \\
& \% \alpha \text {-helix }=\left[\frac{\left(-\mathrm{MRE}_{222}-2340\right)}{30300}\right] \times 100
\end{aligned}
$$

where $\mathrm{MRE}_{208}$ and $\mathrm{MRE}_{222}$ are the observed MRE value at 208 and $222 \mathrm{~nm}$, respectively. 4,000 and 2,340 are the MRE values of the $\beta$-form and random coil conformation cross at 208 and $222 \mathrm{~nm}$, respectively, while, 33,000 and 30,300 are the MRE values of a pure $\alpha$-helix at 208 and $222 \mathrm{~nm}$, respectively. ${ }^{16,17}$

\section{Methodology for molecular docking calculation}

The crystallographic structure of HSA was obtained from the Protein Data Bank (PDB) with access code 1N5U. ${ }^{18}$ This structure has a resolution of $1.90 \AA$ A. The BZL, MTZ, NFX and MZ structures were built and energyminimized with the density functional theory (DFT), method Becke-3-Lee Yang Parr (B3LYP) with the standard 6-31G* basis set available in the Spartan'14 program (Wavefunction, Inc.). ${ }^{19}$ The theoretical solvation energy to each antiparasitic drugs was calculated under the same condition described above.

Molecular docking was performed with the GOLD 5.2 program (CCDC).$^{20}$ Hydrogen atoms were added to the protein according to the data inferred by the program on the ionization and tautomeric states. ${ }^{20}$ Docking interaction cavities explored for the docking procedure were delimited by a $10 \AA$ radius from the Trp-214 residue. The number of genetic operations (crossover, migration, mutation) in each docking run used in the searching procedure was set to 100,000 ; and during the each docking run the amino acid residues were considered as static. The program optimizes hydrogen-bond geometries by rotating hydroxyl and amino groups of the amino acid side chains. The scoring function used was ChemPLP, ${ }^{21}$ which is the default function of the GOLD 5.2 program. The score of each pose identified is calculated as the negative of the sum of a series of energy terms involved in the protein-ligand interaction process, so the more positive the score, the better is the interaction. The figure of the best docking pose for each sample was generated by the PyMOL Delano Scientific LLC program. ${ }^{22}$

\section{Results and Discussion}

\section{Steady state fluorescence quenching studies}

HSA has a single tryptophan residue (Trp-214) located in the hydrophobic cavity of site I. The intrinsic fluorescence emitted by the Trp-214 residue is very sensitive to the environment around this fluorophore. Therefore, Trp-214 fluorescence has been employed frequently in the study of HSA interaction with fatty acids, drugs, or many other exogenous chemical substances. ${ }^{23}$ Figure 2 clearly shows that the tryptophan fluorescence emission decreases with the increase of quencher concentration for all compounds employed in this study. Note that BZL has a lower efficiency in quenching the tryptophan fluorescence emission when compared to MTZ, NFX and MZ. Besides, there is no indication of a significant blue or red shift in the maxima of fluorescence emission upon binding with the quencher samples. Note that a slight observed shift is in the range of the standard deviation of the measurements (Figure 2); this is confirmed by SF spectra (Figure 4). The results clearly indicate that BZL, MTZ, NFX and MZ are binding next to the Trp-214 residue and that the binding does not have any effect on the polarity around the tryptophan residue. ${ }^{24}$

Fluorescence quenching can occur mainly by two types of mechanisms: static and dynamic (or a combination of both). ${ }^{25}$ Table 1 shows that the $\mathrm{k}_{\mathrm{q}}$ values are higher than the diffusion limit rate constant for biomolecules $\left(\mathrm{k}_{\text {diff }}\right.$ ca. $\left.5.00 \times 10^{9} \mathrm{M}^{-1} \mathrm{~s}^{-1}\right){ }^{26}$ indicating that the fluorescence quenching occurs mainly through a static mechanism, which involves initial ground-state association. ${ }^{27,28}$ In addition, for the samples BZL, MTZ and MZ, the $\mathrm{K}_{\mathrm{sv}}$ values decrease with the increasing of temperature, confirming a static fluorescence quenching mechanism; however, for NFX, the $K_{S v}$ values has a slight increase with the increasing of temperature, suggesting the possibility of dynamic fluorescence quenching mechanism also occurring in the binding process. This will be clarified through timeresolved fluorescence studies (see section below). 

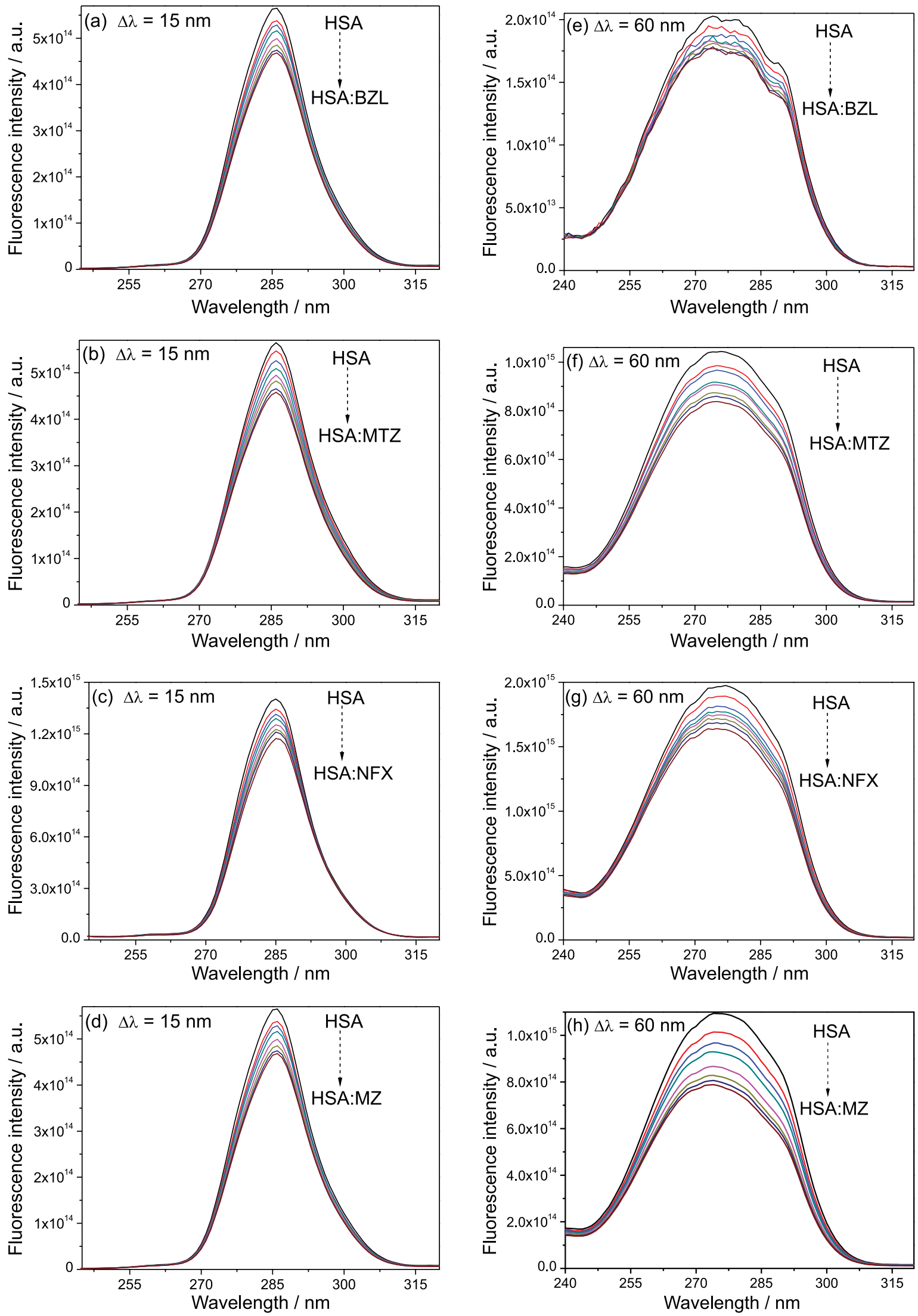

Figure 4. Synchronous fluorescence measurement for HSA without and with the presence of BZL, MTZ, NFX and MZ with $\Delta \lambda=15 \mathrm{~nm}$ for Tyr (a, b, $\mathrm{c}$ and $\mathrm{d}$, respectively) and $\Delta \lambda=60 \mathrm{~nm}$ for $\operatorname{Trp}\left(\mathrm{e}, \mathrm{f}, \mathrm{g}\right.$ and $\mathrm{h}$, respectively). $[\mathrm{HSA}]=1.00 \times 10^{-5} \mathrm{M} ;[\mathrm{BZL}]=[\mathrm{MTZ}]=[\mathrm{NFX}]=[\mathrm{MZ}]=0.17 ; 0.33 ; 0.50$; $0.66 ; 0.83 ; 0.99$ and $1.15 \times 10^{-5} \mathrm{M}$. 
Table 1. Stern-Volmer constants $\left(\mathrm{K}_{\mathrm{SV}}\right)$, quenching rate constants $\left(\mathrm{k}_{\mathrm{q}}\right)$, modified Stern-Volmer binding constants $\left(\mathrm{K}_{\mathrm{a}}\right)$ and thermodynamic parameters $\left(\Delta \mathrm{H}^{\circ}\right.$, $\Delta \mathrm{S}^{\circ}$ and $\Delta \mathrm{G}^{\circ}$ ) for the interaction of BZL, MTZ, NFX and MZ with HSA at three different temperatures

\begin{tabular}{|c|c|c|c|c|c|c|c|c|c|c|}
\hline Code & $\mathrm{T} / \mathrm{K}$ & $\begin{array}{c}\mathrm{K}_{\mathrm{SV}}\left(\times 10^{4}\right) / \\
\mathrm{M}^{-1}\end{array}$ & $\begin{array}{c}\mathrm{k}_{\mathrm{q}}\left(\times 10^{12}\right) / \\
\left(\mathrm{M}^{-1} \mathrm{~s}^{-1}\right)\end{array}$ & $r^{2}$ & $\begin{array}{c}\mathrm{K}_{\mathrm{a}}\left(\times 10^{5}\right) / \\
\mathrm{M}^{-1}\end{array}$ & $r^{2}$ & $\begin{array}{c}\Delta \mathrm{H}^{\circ} / \\
\left(\mathrm{kJ} \mathrm{mol}^{-1}\right)\end{array}$ & $\begin{array}{c}\Delta \mathrm{S}^{\circ} / \\
\left(\mathrm{kJ} \mathrm{mol}^{-1} \mathrm{~K}^{-1}\right)\end{array}$ & $\begin{array}{c}\Delta \mathrm{G}^{\circ} / \\
\left(\mathrm{kJ} \mathrm{mol}^{-1}\right)\end{array}$ & $r^{2}$ \\
\hline & 296 & $0.79 \pm 0.07$ & 1.39 & 0.9994 & $1.95 \pm 0.28$ & 0.9979 & & & -29.9 & \\
\hline \multirow[t]{3}{*}{ BZL } & 303 & $0.75 \pm 0.22$ & 1.32 & 0.9947 & $1.89 \pm 0.28$ & 0.9984 & $-5.34 \pm 0.55$ & $0.083 \pm 0.002$ & -30.5 & 0.9789 \\
\hline & 310 & $0.73 \pm 0.20$ & 1.29 & 0.9963 & $1.77 \pm 0.28$ & 0.9955 & & & -31.1 & \\
\hline & 296 & $0.83 \pm 0.04$ & 1.46 & 0.9829 & $2.61 \pm 0.28$ & 0.9961 & & & -30.7 & \\
\hline \multirow[t]{3}{*}{ MTZ } & 303 & $0.77 \pm 0.03$ & 1.36 & 0.9902 & $2.58 \pm 0.28$ & 0.9938 & $-1.09 \pm 0.02$ & $0.100 \pm 0.007$ & -31.4 & 0.9992 \\
\hline & 310 & $0.69 \pm 0.03$ & 1.21 & 0.9909 & $2.55 \pm 0.28$ & 0.9969 & & & -32.1 & \\
\hline & 296 & $0.83 \pm 0.19$ & 1.46 & 0.9973 & $0.25 \pm 0.28$ & 0.9964 & & & -24.8 & \\
\hline \multirow[t]{3}{*}{ NFX } & 303 & $0.89 \pm 0.27$ & 1.57 & 0.9945 & $0.31 \pm 0.28$ & 0.9941 & $27.6 \pm 2.20$ & $0.177 \pm 0.007$ & -26.0 & 0.9874 \\
\hline & 310 & $0.95 \pm 0.20$ & 1.67 & 0.9968 & $0.41 \pm 0.28$ & 0.9969 & & & -27.3 & \\
\hline & 296 & $2.24 \pm 0.04$ & 3.94 & 0.9982 & $2.22 \pm 0.28$ & 0.9993 & & & -30.4 & \\
\hline \multirow[t]{2}{*}{ MZ } & 303 & $2.09 \pm 0.07$ & 3.68 & 0.9939 & $2.10 \pm 0.28$ & 0.9970 & $-6.15 \pm 0.04$ & $0.082 \pm 0.001$ & -31.0 & 0.9999 \\
\hline & 310 & $1.92 \pm 0.08$ & 3.38 & 0.9903 & $1.98 \pm 0.28$ & 0.9956 & & & -31.6 & \\
\hline
\end{tabular}

$\mathrm{T}$ : temperature; $\mathrm{r}^{2}$ : coefficient of determination (dimensionless); $\Delta \mathrm{G}^{\circ}$ : Gibb's free energy change; $\Delta \mathrm{H}^{\circ}$ : enthalpy change; $\Delta \mathrm{S}^{\circ}$ : entropy change; BZL: benznidazole; MTZ: metronidazole; NFX: nifurtimox; MZ: megazol.

For a static quenching process the modified SternVolmer analysis can be applied to determine the binding constant between HSA and the antiparasitc drugs under study. As can be seen in Table 1, for HSA:BZL, HSA:MTZ and HSA:MZ, the $\mathrm{K}_{\mathrm{a}}$ values are in the order of $10^{5} \mathrm{M}^{-1}$, while for HSA:NFX the $\mathrm{K}_{\mathrm{a}}$ values are in the order of $10^{4} \mathrm{M}^{-1}$, suggesting a high binding affinity between serum albumin and the antiparasitic drugs under study. ${ }^{13,24,29,30}$ For BZL, MTZ and MZ samples, the decrease of $\mathrm{K}_{\mathrm{a}}$ values with the increasing of temperature indicates a decreased stability of the HSA:drug complex at a higher temperature, compatible with the static fluorescence quenching mechanism already mentioned. ${ }^{13,31}$ On the other hand, for NFX, the increase of $\mathrm{K}_{\mathrm{a}}$ values with increasing temperature suggests that at higher temperatures the increased mobility inside the serum albumin structure allows the ligand to find improved binding within the protein pocket.

In general, four representative interaction forces, namely hydrophobic force, hydrogen bond, van der Waals force, and electrostatic interactions, exist between small molecular substrates and biological macromolecules. When the temperature effect is very small, the enthalpy change due to the interaction HSA:small molecule can be regarded as constant, according to the van't Hoff analysis..$^{32}$ Table 1 shows negative $\Delta \mathrm{G}^{\circ}$ values for all samples, in accordance with the spontaneity of the binding process. For BZL, MTZ and MZ, the entropy and enthalpy changes are responsible for the major contribution to the negative sign of $\Delta \mathrm{G}^{\circ}$, indicating that the interaction between HSA with these samples is entropically and enthalpically driven. ${ }^{14,28}$
On the other hand, for NFX only the entropy change is responsible for the major contribution to the negative sign of $\Delta \mathrm{G}^{\circ}$, indicating that the interaction HSA:NFX is entropically driven. ${ }^{31}$

Ross and Subramanian ${ }^{33}$ have characterized the sign of the thermodynamic parameters with various kinds of interaction which may take place in the protein association process. ${ }^{34}$ Table 1 shows that $\Delta \mathrm{H}^{\circ}$ and $\Delta \mathrm{S}^{\circ}$ values are negative and positive, respectively, for HSA:BZL, HSA:MTZ and HSA:MZ, indicating hydrogen bonding and electrostatic forces as the main binding forces in the binding process. ${ }^{35}$ While for HSA:NFX interaction, hydrogen bonding and hydrophobic interaction are the main binding forces. ${ }^{33}$ From the standpoint of water structure, positive entropy is often regarded as a typical signature of hydrophobic interaction, since the water molecules which are arranged in an orderly fashion around the ligand and the protein molecules acquire a more random configuration as a result of hydrophobic interactions..$^{34}$ Other possible sources for entropic contributions like residual flexibility of ligand and/or the protein binding site can also be considered. The negative enthalpy value may be explained when small molecules are partially inserted into a hydrophobic cavity of HSA formed by folding and twisting of the peptide chain. In the present case, the hydrophobic interaction between the antiparasitc drugs and the cavity would cause an exothermic process. ${ }^{34,36}$ Note that BZL, MTZ and MZ structures present similar structural characteristics, with just one (nitro) group with high electron density and $\mathrm{H}$-donors and/or aromatic groups connected to an imidazole ring, 
while the NFX structure is more linear, and has the nitro group in one end (furan, not imidazole), and a second (sulfone) group with high electron density, at the other extremity, with no aromatic group or H-donor in between (Figure 1). In aqueous phase, NFX coordinates with a large number of solvent molecules, using its $\mathrm{H}$-acceptor sites; when NFX penetrates the protein cavity, which is relatively hydrophobic, these molecules are liberated, and the bulk volume previously occupied by NFX is also taken by water; furthermore, water molecules which occupied the protein cavity, are expelled to the external space, where they enjoy the increased degrees of freedom. The net result is an increase in disorder $\left(\Delta S^{\circ}>0\right)$. In terms of enthalpy, the transition from ligand in water solution to ligand in protein cavity (ligand-protein complex) can be seen as involving desolvation of the ligand and formation of new interactions (hydrogen bonds, ionic terms, etc.) inside the cavity. Calculation (semi-quantitative, Spartan'14 DFT B3LYP) of solvation energies for the four ligand molecules gives negative values in all cases, but more so for NFX: $-36.07,-45.31,-52.64$ and $-64.46 \mathrm{~kJ} \mathrm{~mol}^{-1}$, for BZL, MTZ, MZ and NFX, respectively, thus, positive values for the inverse, desolvation process. For BZL, MTZ and MZ this is compensated by stabilizing interactions inside the cavity. NFX not only has the larger desolvation value, but also lacks H-bond donor groups; thus, in this case, $\Delta \mathrm{H}^{\circ}>0$.

\section{Time-resolved fluorescence studies}

Time-resolved fluorescence is a sensitive spectroscopic technique widely used to explore the interaction between proteins and ligands through the decay profile of the excited state of fluorophore in the absence and presence of quenchers. ${ }^{14}$ HSA has only one tryptophan residue (main HSA's fluorophore), therefore the fluorescence lifetime decay of Trp-214 was observed in order to further confirm which type of fluorescence quenching mechanism is involved in the HSA:BZL, HSA:MTZ, HSA:NFX and HSA:MZ interaction. The fluorescence decay profiles of the native HSA and HSA associated with each ligand are shown in Figure 5. These data indicate that the fluorescence lifetime of free HSA and HSA associated with each antiparasitc drug is the same inside the experimental error, for both fluorescence lifetime components $\left(\tau_{1}\right.$ and $\tau_{2}$, Table 2). Since the fluorescence lifetime of HSA is unaffected by the presence of BZL, MTZ, NFX or MZ at a concentration of $1.15 \times 10^{-5} \mathrm{M}$, one can conclude that the fluorescence quenching mechanism is static, which implies a groundstate association between the tryptophan residue in HSA and the antiparasitic drugs..$^{11,14}$ These results are in total accordance with the results shown above for the steady state fluorescence quenching (ground-state association, Table 1).
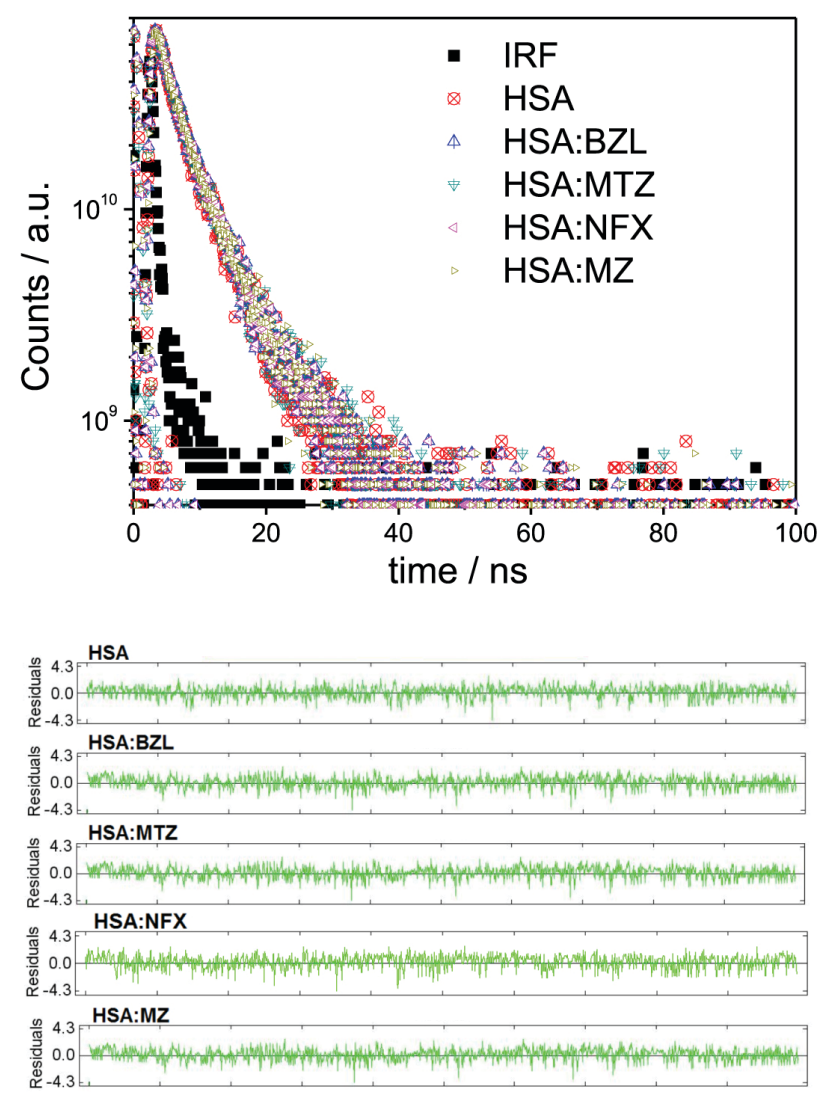

Figure 5. (Top) Time-resolved fluorescence decays and (bottom) its residuals for HSA solution and HSA:BZL, HSA:MTZ, HSA:NFX, and HSA:MZ in $\mathrm{pH}=7.40$. $[\mathrm{HSA}]=1.00 \times 10^{-5} \mathrm{M}$; $[\mathrm{BZL}]=[\mathrm{MTZ}]=[\mathrm{NFX}]=[\mathrm{MZ}]=1.15 \times 10^{-5} \mathrm{M}$ at room temperature.

Table 2. Fluorescence lifetimes for free HSA and HSA:BZL, HSA:MTZ, HSA:NFX and HSA:MZ at room temperature and $\mathrm{pH}=7.40$

\begin{tabular}{lccccc}
\hline Code & $\tau_{1} / \mathrm{ns}$ & Component $1 / \%$ & $\tau_{2} / \mathrm{ns}$ & Component $2 / \%$ & $\chi^{2}$ \\
\hline HSA & $1.78 \pm 0.11$ & 26.5 & $5.68 \pm 0.10$ & 73.5 & 1.100 \\
HSA:BZL & $1.64 \pm 0.12$ & 21.8 & $5.53 \pm 0.09$ & 78.2 & 1.073 \\
HSA:MTZ & $1.66 \pm 0.11$ & 23.6 & $5.63 \pm 0.10$ & 76.4 & 1.023 \\
HSA:NFX & $1.65 \pm 0.10$ & 22.0 & $5.52 \pm 0.10$ & 78.0 & 1.020 \\
HSA:MZ & $1.72 \pm 0.11$ & 27.0 & $5.65 \pm 0.11$ & 73.0 & 1.091 \\
\hline
\end{tabular}

HSA: human serum albumin; BZL: benznidazole; MTZ: metronidazole; NFX: nifurtimox; MZ: megazol; $\chi^{2}$ (chi squared): measures the goodness of fit of experimental data to a bi-exponential decay for HSA fluorescence. ${ }^{37}$ 


\section{Synchronous fluorescence studies}

Synchronous mode of fluorescence spectroscopy is a sensitive technique applied to study the effect of the binding of small molecules on the molecular environment in the vicinity of a chromophore. This technique allows the study of the conformational changes on the protein structure by scanning the excitation and emission monochromators simultaneously, while maintaining a constant wavelength interval $(\Delta \lambda)$ between them. When $\Delta \lambda$ is fixed at 15 or $60 \mathrm{~nm}$, the synchronous fluorescence gives characteristic information on the tyrosine or tryptophan residues, respectively. ${ }^{14,38,39}$ Synchronous fluorescence spectra of HSA with different concentrations of each drug at $\Delta \lambda$ of 15 and $60 \mathrm{~nm}$ are shown in Figure 4.

The maximum fluorescence emission wavelength for Tyr and Trp residues shows no significant shift upon successive addition of BZL, MTZ, NFX or MZ, indicating that the microenvironment around the Tyr and Trp residues is not disturbed by the binding of the antiparasitic drugs under study. ${ }^{11}$ These results clearly confirm the data obtained by the steady state fluorescence quenching, i.e., the binding does not have any effect on the polarity around the tryptophan residue. The synchronous fluorescence results also suggest that the conformation of HSA did not change upon interaction with BZL, MTZ, NFX or MZ. ${ }^{14,40}$

\section{Perturbation on the secondary structure of the albumin}

In order to determine the existence of a possible perturbation on the secondary structure of the albumin upon binding of BZL, MTZ, NFX and MZ at the maximum concentration employed in the binding study described above $\left(1.15 \times 10^{-5} \mathrm{M}\right)$, circular dichroism (CD) experiments were carried out at $310 \mathrm{~K}$. The $\mathrm{CD}$ spectrum of HSA exhibited two negative bands in the UV region at 208 and $222 \mathrm{~nm}$, characteristic of the $\alpha$-helical $\pi-\pi^{*}$ and $n-\pi *$ transition, respectively. ${ }^{41}$ Figure 6 shows a clear decrease in the CD signal upon the addition of each antiparasitc drugs, indicating that there is a perturbation on the secondary structure of the albumin upon ligand binding. ${ }^{42}$

Quantitatively, the $\alpha$-helix percent decreases gradually from $63.1 \%$ in free HSA to 62.7, 61.4, 61.1 and 59.5\% upon MTZ, BZL, MZ or NFX binding, respectively, at $208 \mathrm{~nm}$. Similarly, at $222 \mathrm{~nm}$ the $\alpha$-helix percent decreases gradually from $59.5 \%$ in free HSA to 58.9, 58.8, 58.2, and 57.4\% upon MZ, MTZ, BZL or NFX binding, respectively. The $\mathrm{CD}$ results indicate a slight perturbation of the albumin structure upon binding of the samples, but the binding does not affect significantly the $\alpha$-helical content. ${ }^{41,43}$

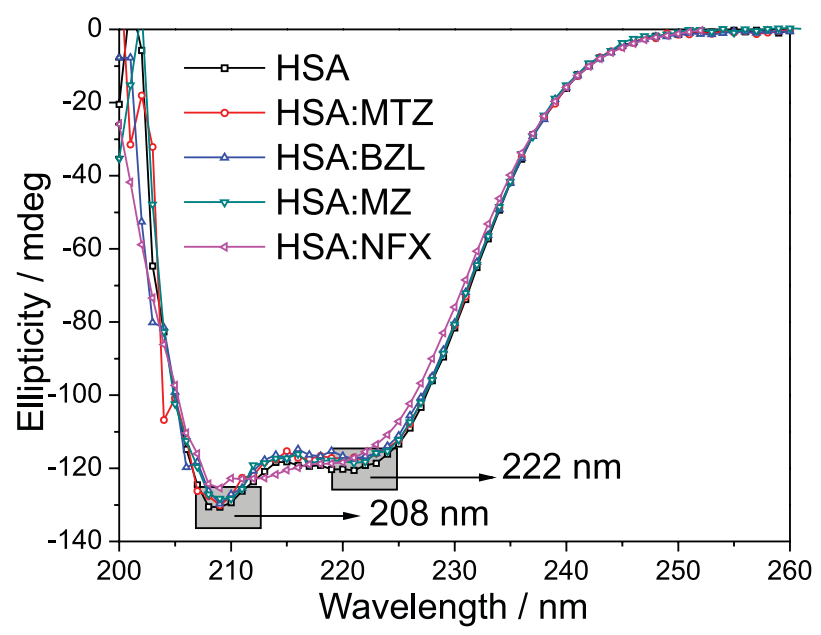

Figure 6. Circular dichroism spectra for the association HSA:BZL, HSA:MTZ, HSA:NFX and HSA:MZ in $\mathrm{pH}=7.40$ at $310 \mathrm{~K}$. $[\mathrm{HSA}]=1.00 \times 10^{-6} \mathrm{M} ;[\mathrm{BZL}]=[\mathrm{MTZ}]=[\mathrm{NFX}]=[\mathrm{MZ}]=1.15 \times 10^{-5} \mathrm{M}$.

\section{D fluorescence studies}

Three-dimensional fluorescence spectroscopy (3D) can provide detailed information on the structural changes of the polypeptide backbone. In addition, changes on polarity of the microenvironment around the Trp and Tyr residues, due to increased exposure of some previously buried hydrophobic regions, cause changes on peaks I (reflects $\pi-\pi^{*}$ transition of the $\mathrm{C}=\mathrm{O}$ ) and II (reflects $\pi-\pi^{*}$ transition of fluorophores), respectively. ${ }^{44}$ Peaks $\mathrm{a}\left(\lambda_{\mathrm{ex}}=\lambda_{\mathrm{em}}\right)$ and $\mathrm{b}\left(2 \lambda_{\mathrm{ex}}=\lambda_{\mathrm{em}}\right)$ are referred as Rayleigh and second order scattering peaks, respectively. ${ }^{45}$ The corresponding 3D spectra of HSA in the absence or in the presence of BZL, MTZ, NFX and MZ are shown in Figure 3. As shown in the figure, the emission intensity decreases upon the addition of each antiparasitic drugs to HSA. Besides, the absence of significant change on the position of the maximum fluorescence intensity implies that there is formation of a ground state nonfluorescent complex between the fluorophore and the biomolecule, as well as there is not significant perturbation on protein structure and on microenvironment around Trp and Tyr residues. ${ }^{46,47}$ These results clearly confirm the data obtained by $\mathrm{CD}$, steady state and synchronous fluorescence techniques described above.

\section{Competitive binding studies}

In general, the main regions of small molecules binding sites on HSA are located in the hydrophobic cavities in subdomains IIA and IIIA, which are also referred as Sudlow's site I and site II, respectively, according to the terminology proposed by Sudlow et al..$^{48}$ Furthermore, the hydrophilic cavity located in sub-domain IB, which is referred as site III, 
is also considered as a possible protein pocket for small molecules. ${ }^{40}$ In order to identify the main protein cavity for the association of BZL, MTZ, NFX and MZ, competitive binding studies were performed at $310 \mathrm{~K}$ using different site probes, namely warfarin, ibuprofen and digitoxin for sites I, II and III, respectively. Figure S4 (SI section) displays the modified Stern-Volmer plots for HSA:BZL, HSA:MTZ, HSA:NFX and HSA:MZ in the presence of each site probe.

The $\mathrm{K}_{\mathrm{a}}$ values, obtained from equation 3, clearly decreased in the presence of warfarin, ibuprofen and digitoxin at $310 \mathrm{~K}$, indicating that there is a competition between the site markers and the antiparasitc drugs (Table 3). However, a larger decrease in $\mathrm{K}_{\mathrm{a}}$ values can be observed in the presence of warfarin $(39.3,47.5,62.1$ and $63.2 \%$ for NFX, MTZ, BZL and MZ, respectively), indicating that the hydrophobic cavity of the protein in sub-domain IIA (Sudlow's site I), where the fluorophore Trp-214 can be found, is the main binding site for the antiparasitc drugs under studies. ${ }^{43}$

Table 3. Modified Stern-Volmer binding constant values $\left(K_{a}\right)$ for the interaction of BZL, MTZ, NFX and MZ with HSA in the presence of three different site markers (warfarin, ibuprofen and digitoxin) at $310 \mathrm{~K}$

\begin{tabular}{lcccc}
\hline Code & $\begin{array}{c}\text { Site } \\
\text { marker }\end{array}$ & $\begin{array}{c}\text { Specific } \\
\text { site }\end{array}$ & $\mathrm{K}_{\mathrm{a}} / \mathrm{M}^{-1}$ & $\mathrm{r}^{2}$ \\
\hline \multirow{4}{*}{ BZL } & warfarin & I & $(0.67 \pm 0.19) \times 10^{5}$ & 0.97741 \\
& ibuprofen & II & $(0.87 \pm 0.22) \times 10^{5}$ & 0.9929 \\
& digitoxin & III & $(0.99 \pm 0.18) \times 10^{5}$ & 0.9861 \\
\hline \multirow{4}{*}{ MTZ } & warfarin & I & $(1.34 \pm 0.20) \times 10^{5}$ & 0.9926 \\
& ibuprofen & II & $(1.80 \pm 0.21) \times 10^{5}$ & 0.9985 \\
& digitoxin & III & $(2.00 \pm 0.20) \times 10^{5}$ & 0.9908 \\
\hline \multirow{4}{*}{ NFX } & warfarin & I & $(2.49 \pm 0.28) \times 10^{4}$ & 0.9986 \\
& ibuprofen & II & $(3.50 \pm 0.28) \times 10^{4}$ & 0.9841 \\
& digitoxin & III & $(4.08 \pm 0.28) \times 10^{4}$ & 0.9968 \\
\hline \multirow{4}{*}{ MZ } & warfarin & I & $(7.28 \pm 0.18) \times 10^{4}$ & 0.9861 \\
& ibuprofen & II & $(7.48 \pm 0.20) \times 10^{4}$ & 0.9880 \\
& digitoxin & III & $(7.97 \pm 0.19) \times 10^{4}$ & 0.9931 \\
\hline
\end{tabular}

$\mathrm{r}^{2}$ : coefficient of determination (dimensionless); BZL: benznidazole; MTZ: metronidazole; NFX: nifurtimox; MZ: megazol.

\section{Molecular docking studies}

The computational study by molecular docking is a common technique which is used efficiently to analyze the main intermolecular interactions between small molecules and macromolecules. ${ }^{49}$ In order to offer more details about the interaction between the antiparasitic drugs BZL, MTZ, NFX and MZ with HSA, a molecular docking exercise was carried out.

The spectroscopic results discussed above showed that the addition of each antiparasitic drug to an HSA solution quenches the intrinsic fluorescence of serum albumin, and the competitive binding studies clearly indicate that the antiparasitic drugs under studies are located next to the fluorophore the Trp-214 residue. The cavity where this amino acid residue can be found is located in the subdomain IIA. ${ }^{43}$

In agreement with the experimental results, we suggest from the docking results that the antiparasitic drugs BZL, MTZ, NFX and MZ are able to be accommodated in the cavity next to the Trp-214 residue, presenting a favorable interaction profile with the cavity residues. The molecular docking results suggest that the aromatic ring of BZL interacts via hydrophobic interaction with the Trp-214 residue, within a distance of $3.40 \AA$ (Figure 7a). The hydrogen of the amide group of Gln-220 residue interacts via hydrogen bonding with the nitrogen of the imidazole ring (nitrogen on the position three of the aromatic ring) within a distance of $3.79 \AA$ A. Similarly, the guanidinium group of Arg-221 residue is also able to interact via hydrogen bonding with the oxygen of the nitro group in the BZL structure, within a distance of $1.59 \AA$. The carboxyl group of Glu-449 residue is hydrogen bonded to the hydrogen of the amine group in the BZL structure.
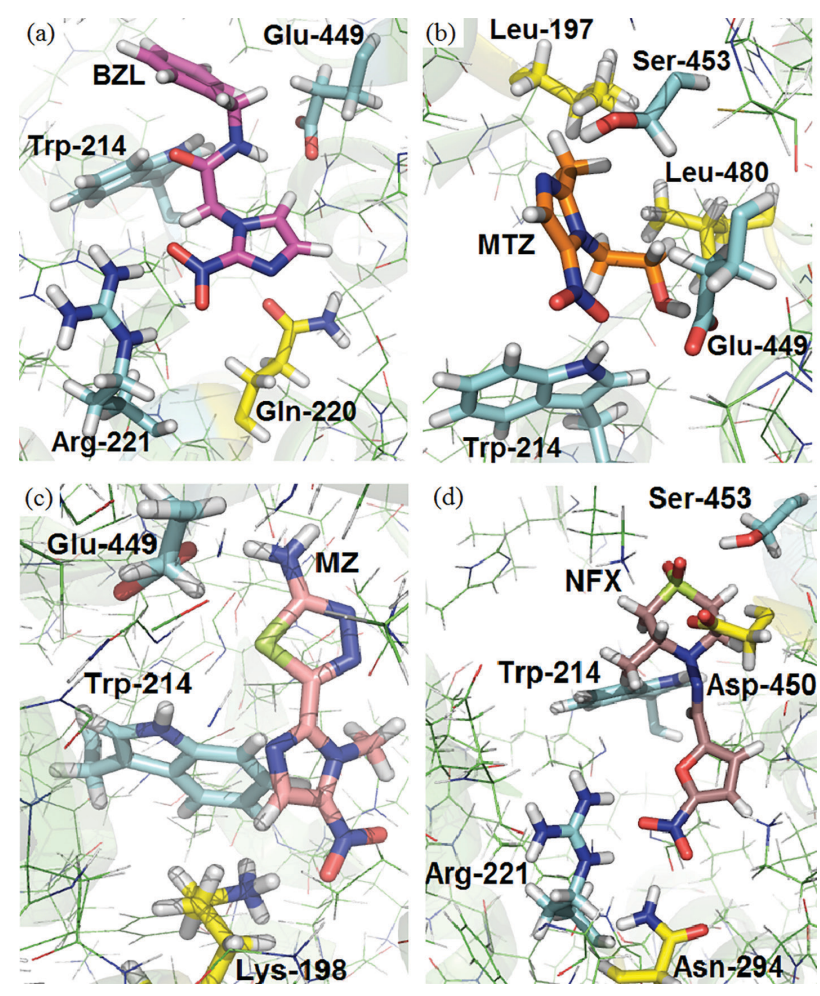

Figure 7. Best docking score pose for (a) HSA:BZL; (b) HSA:MTZ; (c) HSA:MZ and (d) HSA:NFX obtained by using the GOLD 5.2 program (ChemPLP function). ${ }^{21}$ BZL, MTZ, MZ and NFX structure are represented in pink, orange, beige and brown, respectively. The HSA structure is shown in green color (PDB: 1N5U). The select amino acids residues are in yellow, while the same residues that participate in the interactions with one more drug are highlighted in cyan. Hydrogen: white; oxygen: red; sulfur: light green; nitrogen: blue. 
On the other hand, molecular docking results for the HSA:MTZ association (Figure 7b) suggest that the indole group of the Trp-214 residue is able to show hydrogen bonding with the oxygen of the nitro group within a distance of $1.91 \AA$. The hydroxyl group of the Ser- 453 residue is hydrogen bonding with the nitrogen of the imidazole ring (nitrogen of the position three of the aromatic ring), within a distance of $2.11 \AA$. The carboxyl group of the Glu-449 residue is hydrogen bonding with the hydroxyl group of the MTZ structure with a distance of $1.93 \AA$ A. Hydrophobic interactions between the Leu-197 and Leu-480 residues and the methyl group of MTZ were also observed.

In addition, molecular docking results for HSA:MZ (Figure 7c) suggest a hydrophobic interaction ( $t$-stacking) between the Trp-214 residue and the imidazole ring of MZ within a distance of $2.98 \AA$, as well as hydrogen bonding between the carboxyl group of Glu-449 residue and the amine group of the ligand. An electrostatic interaction was also detected between the nitro group of MZ and the Lys-198 residue, within a distance of $1.94 \AA$.

Finally, for the interaction HSA:NFX (Figure 7d), molecular docking results suggest hydrogen bonding between the oxygens from the nitro group of the NFX structure with Arg-221 and Asn-294 residues, within a distance of $2.00 \AA$ for both amino acids residues. Ser-453 residue has a donor group for hydrogen bonding with the sulfone group of the ligand structure, within a distance of $2.10 \AA$, while the amino acid residue Asp-450 is electrostatically interacting with the ligand structure. On the other hand, the Trp-214 residue is interacting with the ligand structure via hydrophobic interaction, within a distance of $1.70 \AA$.

The intermolecular interactions suggested by the molecular docking results are in good agreement with the thermodynamic parameters obtained via spectroscopic analysis discussed according to the Ross and Subramanian theory. ${ }^{27}$

\section{Conclusions}

The antiparasitic drugs (BZL, MTZ, NFX and MZ) bind moderately in Sudlow's site I and do not perturb significantly the secondary structure of the albumin. The $\mathrm{k}_{\mathrm{q}}$ and fluorescence lifetime values suggest that the fluorescence quenching of the intrinsic fluorophore of the albumin is via a static mechanism, indicating associations HSA:BZL, HSA:MTZ, HSA:NFX and HSA:MZ in the ground state. Thermodynamic parameters show the spontaneity of the binding process $\left(\Delta \mathrm{G}^{\circ}<0\right)$, which is enthalpically and entropically driven for BZL, MTZ and MZ, while for NFX it is entropically driven. The enthalpy and entropy change values indicate hydrogen bonding and electrostatic forces as the main binding forces for the HSA:BZL, HSA:MTZ and HSA:MZ associations. On the other hand, for the HSA:NFX interaction, hydrogen bonding and hydrophobic interaction are the main binding forces. Synchronous fluorescence suggested that the drugs do not have any effect on the polarity around the Tyr and Trp residues. Molecular docking results suggest that BZL can interact with the Trp-214, Gln-220, Arg-221 and Glu449 residues of HSA, whereas Leu-197, Trp-214, Glu-449, Ser-453 and Leu-480 interact with MTZ, as well as Lys198, Trp-214 and Glu-449 with MZ, and Trp-214, Arg-221, Asn-294, Asp-450 and Ser-453 with NFX. Thus, BZL, MTZ, NFX and MZ can be carried and biodistributed in the human bloodstream by the serum albumin. NFX showed differences in the thermodynamic parameters, probably due to the fact of the differences in the chemical groups present in its structure. The presence of the thiadiazole group in the MZ structure increased its interaction with HAS, which was shown by the better binding parameters.

\section{Supplementary Information}

Supplementary data (UV-Vis spectra, modified SternVolmer and van't Hoff plots) are available free of charge at http://jbcs.sbq.org.br as PDF file.

\section{Acknowledgments}

The authors gratefully acknowledge the Brazilian agencies: Coordenação de Aperfeiçoamento de Pessoal de Nível Superior (CAPES), Conselho Nacional de Desenvolvimento Científico e Tecnológico (CNPq) and Fundação de Amparo à Pesquisa do Estado do Rio de Janeiro (FAPERJ) for financial support. The authors also acknowledge the collaboration of Dr Nanci Camara de Lucas Garden (UFRJ) for her active help during time-resolved, synchronous and 3D fluorescence measurements. We wish to thank Dr Mayara Maria Lima (Chaga's Disease Group of the Health Ministry, Brazilian Government (Grupo Técnico de Doenças de Chagas/UVTV/CGDT/DEVEP/SVS, Ministério da Saúde)), for the donation of a pack of Lampit ${ }^{\circledR}$ tablets, from which the NFX sample was extracted.

\section{References}

1. Messenger, L. A.; Miles, M. A.; Bern, C.; Expert Rev. AntiInfect. Ther. 2015, 13, 995.

2. Bern, C.; N. Engl. J. Med. 2015, 373, 456.

3. Blandón, R.; Johnson, C. M.; Sousa, O.; Leandro, I.; Guevara, J. F.; Rev. Med. Panama 1993, 18, 94. 
4. Lopes, M. S.; Júnior, P. A. S.; Lopes, A. G. F.; Yoshida, M. I.; da Silva, T. H. A.; Romanha, A. J.; Alves, R. J.; de Oliveira, R. B.; Mem. Inst. Oswaldo Cruz 2011, 106, 1055.

5. Poli, P.; de Mello, M. A.; Buschini, A.; Mortara, R. A.; de Albuquerque, C. N.; da Silva, S.; Rossi, C.; Araújo, T. M.; Zucchi, D.; Biochem. Pharmacol. 2002, 64, 1617.

6. Chauvière, G.; Bouteille, B.; Enanga, B.; de Albuquerque, C.; Croft, S. L.; Dumas, M.; Périé, J.; J. Med. Chem. 2003, 46, 427.

7. Carvalho, A. S.; Menna-Barreto, R. F. S.; Romeiro, N. C.; de Castro, S. L.; Boechat, N.; Med. Chem. 2016, 3, 460.

8. Li, X.; Wang, S.; New J. Chem. 2015, 39, 386.

9. Bhattacharyaa, A. A.; Grüne, T.; Curry, S.; J. Mol. Biol. 2000, 303, 721.

10. Fasano, M.; Curry, S.; Terreno, E.; Galliano, M.; Fanali, G.; Narciso, P.; Notari, S.; Ascenzi, P.; IUBMB Life 2005, 57, 787.

11. Bi, S.; Zhao, T.; Zhou, H.; Wang, Y.; Li, Z.; J. Chem. Thermodyn. 2016, 97, 113.

12. Chaves, O. A.; Mathew, B.; Cesarin-Sobrinho, D.; Lakshminarayanan, B.; Joy, M.; Mathew, G. E.; Suresh, J.; Netto-Ferreira, J. C.; J. Mol. Liq. 2017, 242, 1018.

13. Kalalbandi, V. K. A.; Seetharamappa, J.; MedChemComm 2015, 6, 1942.

14. Chaves, O. A.; Cesarin-Sobrinho, D.; Sant'Anna, C. M. R.; Carvalho, M. G.; Suzart, L. R.; Catunda-Junior, F. E. A.; Netto-Ferreira, J. C.; Ferreira, A. B. B.; J. Photochem. Photobiol., A 2017, 336, 32.

15. Chaves, O. A.; Teixeira, F. S. M.; Guimarães, H. A.; Braz-Filho, R.; Vieira, I. J. C.; Sant'Anna, C. M. R.; Netto-Ferreira, J. C.; Cesarin-Sobrinho, D.; Ferreira, A. B. B.; J. Braz. Chem. Soc. 2017, 28, 1229.

16. Zhang, W.; Wang, F.; Xiong, X.; Ge, Y.; Liu, Y.; J. Chil. Chem. Soc. 2013, 58, 1717.

17. Varlan, A.; Hillebrand, M.; Molecules 2010, 15, 3905.

18. Wardell, M.; Wang, Z.; Ho, J. X.; Robert, J.; Ruker, F.; Ruble, J.; Carter, D. C.; Biochem. Biophys. Res. Commun. 2002, 291, 813.

19. Hehre, W. J.; A Guide to Molecular Mechanics and Quantum Chemical Calculations; Wavefunction, Inc.: Irvine, USA, 2003.

20. http://www.ccdc.cam.ac.uk/solutions/csd-discovery/ components/gold/, accessed in December 2017.

21. Korb, O.; Stützle, T.; Exner, T. E.; J. Chem. Inf. Model. 2009, 49,84

22. DeLano, W. L.; PyMOL User's Guide; DeLano Scientific LLC: San Carlos, CA, USA, 2002.

23. Shao, X.; Ai, N.; Xu, D.; Fan, X.; Spectrochim. Acta, Part A 2016, $161,1$.

24. Chaves, O. A.; Amorim, A. P. O.; Castro, L. H. E.; Sant'Anna, C. M. R.; de Oliveira, M. C. C.; Cesarin-Sobrinho, D.; NettoFerreira, J. C.; Ferreira, A. B. B.; Molecules 2015, 20, 19526.

25. Lakowicz, J. R.; Principles of Fluorescence Spectroscopy, $3^{\text {rd }}$ ed.; Springer: New York, USA, 2006.
26. Brune, D.; Kim, S.; Biophysics 1993, 90, 3835.

27. Zhang, S.-L.; Chang, J.-J.; Damu, G. L. V.; Geng, R.-X.; Zhou, C.-H.; MedChemComm 2013, 4, 839.

28. Chaves, O. A.; Jesus, C. S. H.; Henriques, E. S.; Brito, R. M. M.; Serpa, C.; Photochem. Photobiol. Sci. 2016, 15, 1524.

29. Jattinagoudar, L.; Meti, M.; Nandibewoor, S.; Chimatadar, S.; Spectrochim. Acta, Part A 2016, 156, 164.

30. Chaves, O. A.; de Oliveira, C. H. C. S.; Ferreira, R. C.; Pereira, R. P.; de Melos, J. L. R.; Rodrigues-Santos, C. E.; Echevarria, A.; Cesarin-Sobrinho, D.; J. Fluorine Chem. 2017, 199, 103.

31. Chaves, O. A.; Jesus, C. S. H.; Cruz, P. F.; Sant'Anna, C. M. R.; Brito, R. M. M.; Serpa, C.; Spectrochim. Acta, Part A 2016, 169, 175.

32. Zhang, X.; Gao, R.; Li, D.; Yin, H.; Zhang, J.; Cao, H.; Zheng, X.; Spectrochim. Acta, Part A 2015, 136, 1775.

33. Ross, P. D.; Subramanian, S.; Biochemistry 1981, 20, 3096.

34. Li, X.; Hao, Y.; J. Mol. Struct. 2015, 1091, 109.

35. Chaves, O. A.; Soares, B. A.; Maciel, M. A. M.; Sant'Anna, C. M. R.; Netto-Ferreira, J. C.; Cesarin-Sobrinho, D.; Ferreira, A. B. B.; J. Braz. Chem. Soc. 2016, 27, 1858.

36. Sun, D. Z.; Li, L.; Qiu, X. M.; Liu, F.; Yin, B. L.; Int. J. Pharm. 2006, 316, 7.

37. Valeur, B.; Berberan-Santos, M. N.; Molecular Fluorescence: Principles and Applications, $2^{\text {nd }}$ ed.; Wiley-VCH: Weinheim, Germany, 2013.

38. Li, H.; Wu, F.; Tan, J.; Wang, K.; Zhang, C.; Zheng, H.; Hu, F.; J. Pharm. Biomed. Anal. 2016, 122, 21.

39. Khan, S. N.; Islam, B.; Yennamalli, R.; Sultan, A.; Subbarao, N.; Khan, A. U.; Eur. J. Pharm. Sci. 2008, 35, 371.

40. Manivel, A.; Anandan, S.; Colloids Surf., A 2012, 395, 38.

41. Matei, I.; Hillebrand, M.; J. Pharm. Biomed. Anal. 2010, 51, 768.

42. Matei, I.; Ionescu, S.; Hillebrand, M.; J. Lumin. 2011, 131, 1629.

43. Sun, Z.; Xu, H.; Cao, Y.; Wang, F.; Mi, W.; J. Mol. Liq. 2016, $219,415$.

44. Tang, B.; Huang, Y.; Ma, X.; Liao, X.; Wang, Q.; Xiong, X.; Li, H.; Food Chem. 2016, 212, 434.

45. Nasruddin, A. N.; Feroz, S. R.; Mukarram, A. K.; Mohamad, S. B.; Tayyab, S.; J. Lumin. 2016, 174, 77.

46. Sharma, A. S.; Anandakumar, S.; Ilanchelian, M.; J. Lumin. 2014, 151, 206.

47. Meti, M. D.; Nandibewoor, S. T.; Chimatadar, S. A.; Monatsh. Chem. 2014, 145, 1519.

48. Sudlow, G.; Birkett, D. J.; Wade, D. N.; Mol. Pharmacol. 1976, 12,1052 .

49. Paal, K.; Shkarupin, A.; Beckford, L.; Bioorg. Med. Chem. 2007, 15, 1323.

Submitted: December 14, 2017

Published online: February 20, 2018 